\title{
Editor's Essay: The Critical Need for Crisis and Risk Communication Research
}

\author{
Brooke Fisher Liu
}

Department of Communication, University of Maryland College Park, College Park, Maryland, USA

\begin{abstract}
Risk and crisis communication are growing areas of scholarship ripe for multidisciplinary contributions. In this essay, the Volume 2.1 editor reflects on the primary purpose of the Journal of International Crisis and Risk Communication Research and the areas of scholarship the journal promotes. The editor offers advice for researchers and professionals interested in publishing in the journal. Additionally, the editor calls for the community to continue to submit their best research and to support the development of the next generation of risk and crisis communication scholars.
\end{abstract}

KEYWORDS: Risk; crisis; emergency

As I write this essay, I am on a plane flying from the United States to Hong Kong on the 17th anniversary of the September 11, 2001, terrorist attacks. Hurricane Florence is barreling toward the East Coast of the United States, and Super Typhoon Mangkut is predicted to make a direct hit on Hong Kong this weekend. The societal importance of risk and crisis communication has never been clearer.

The September 11 attacks and Hurricane Katrina occurred while I was in graduate school and inspired my interest in government risk and crisis communication research. At the time, we had insufficient scholarship, especially scholarship that might help governments prepare their communities to respond to disasters. Scholarship on nonprofit risk and crisis communication was also lacking, and corporate crisis communication research was in the early stages of theoretical development. Today, we have a proliferation of research on risk and crisis

CONTACT Brooke Fisher Liu • E-mail: bfliu@umd.edu • Department of Communication, University of Maryland College Park, 4300 Chapel Dr., College Park, MD 20740, USA

๑ 2019 by Journal of International Crisis and Risk Communication Research. All rights reserved. 
communication on a variety of topics, including infectious diseases, public health interventions, disasters, terrorism, environmental issues, and misdeeds by organizations and their leaders. We have become a large, vibrant community. Yet, we still have more questions than answers about how to effectively communicate about risks and crises.

This journal provides the first dedicated outlet for crisis and risk communication scholarship. As an open access journal, it also disseminates our scholarship for researchers and professionals around the world.

As former editor Dr. Matt Seeger (2018) noted,

this journal, more than 15 years in the making, grew out of a recognition that crisis and risk communication are growing research topics with important applied, global, and interdisciplinary dimensions. This diverse body of research follows a variety of methodological and epistemic traditions, and although other traditional outlets for communication scholarship have been open to publishing crisis and risk research, the volume of work warrants a dedicated journal. (p. 8)

We are a journal for all scholars and professionals interested in risk and crisis communication, and we welcome research from disciplines such as emergency management, emergency medicine, business, public health, sociology, data sciences, political science, psychology, public administration, and, of course, communication. We are a multimethodological journal, supporting research approaches ranging from historical/critical, qualitative, or quantitative to computational methods. Additionally, we support state-of-the-art review essays.

As the second editor of this journal, I often receive queries about what type of research is and is not deserving of publication in this journal. As a community, we get to answer that question by the work that we submit to the journal. In case that answer is unsatisfactory for authors interested in submitting their work to our journal, let me offer a few pieces of advice.

First, this is not the journal to send the paper that was rejected from all other journals. Nor is it the place to submit the small amount of remaining data from a project after publishing key research findings 
elsewhere. We are building the first and premier journal for crisis and risk communication research. We need the community's support in achieving this mission.

Second, this journal seeks to develop new approaches, theories, and insights about crisis and risk communication. In other words, we are unlikely to publish research that tests existing knowledge with limited advancement.

Third, this journal takes an expansive view on crisis and risk communication. For detailed discussions defining crisis and risk communication, see Coombs (2014), Rasmussen and Ihlen (2017), and Reynolds and Seeger (2005). We are interested in scholarship that focuses on organizations and their leaders. Additionally, we are interested in scholarship on communities and publics, including how they interact with organizations. We advance scholarship on preparedness, response, and recovery.

Fourth, and perhaps most importantly, we are an international journal. We warmly encourage research from around the globe, including from new and established scholars and professionals.

Lastly, our journal has a dual mission of extending theory and practice. Thus, all submitted manuscripts must advance the science of crisis and risk communication, including through improving professionals' knowledge about practice.

In this third issue of the journal, we feature scholarship that advances measurement of risk and crisis communication constructs and understanding of emergency risk communication. Lee and Jin's study develops a new scale for crisis information seeking and sharing and then validates this scale in the context of public health crises. Risk and crisis communication during public health emergencies remains an undertheorized and undermeasured area of our scholarship, which this study helps address.

Zhou, Ki, and Brown's study proposes a definition of perceived crisis severity and develops a new, validated scale to measure this construct. Crisis severity is at the heart of much of our research on attribution of crisis responsibility, but this is the first study to operationalize and measure that construct.

Novak and colleagues' study provides a mixed-method systematic 
review of engaging communities in emergency risk and crisis communication. Through providing a detailed review, this study provides critical knowledge for professionals to better engage their communities. Findings also identify key research gaps, given that we rarely take a community engagement approach to our research.

Avery's article extends the crisis and emergency risk communication (CERC) model to the context of public information officers responding to a global pandemic. Results illuminate risk and crisis communication challenges that public health departments face and extend the CERC model.

Sellnow, Parrish, and Semenas's invited essay examines how claims of crises as hoaxes disrupt the discourse of renewal, which inhibits communities' crisis recovery. The study investigates a unique crisis type and extends theory. Like all articles in this issue, it clearly advances research and practice.

When I was in graduate school, Drs. Timothy Sellnow (the journal's editor-in-chief) and Matthew Seeger (the journal's former editor) were my role models. It is an honor to work with them on building this journal. In doing so, we provide a new home for the multidisciplinary research on crisis and risk communication, including fostering the next generation of scholars. Through our research, we can contribute to building a more agile and resilient society.

Dr. Brooke Liu researches how government messages, media, and interpersonal communication can motivate people to successfully respond to and recover from disasters. Liu is an associate professor of communication at the University of Maryland, where she leads the Risk Communication and Resilience Research Program at START, a U.S. Department of Homeland Security Center of Excellence. Liu's research has been funded by government agencies such as the Defense Advanced Research Projects Agency (DARPA), the Department of Homeland Security (DHS), the National Science Foundation (NSF), and the National Oceanic and Atmospheric Administration (NOAA). 


\section{References}

Coombs, W. T. (2014). Ongoing crisis communication: Planning, managing, and responding. Thousand Oaks, CA: Sage.

Rasmussen, J., \& Ihlen, Ø. (2017). Risk, crisis, and social media: A systematic review of seven years' research. Nordicom Review, 38, 1-17. https://doi.org /10.1515/nor-2017-0393

Reynolds, B., \& Seeger, M. W. (2005). Crisis and emergency risk communication as an integrative model. Journal of Health Communication, 10, 43-55. https://doi.org/10.1080/10810730590904571

Seeger, M. W. (2018). Answering the call for scholarship: The Journal of International Crisis and Risk Communication Research. Journal of International Crisis and Risk Communication Research, 1, 7-10. https://doi.org/10.30658 /jicrcr.1.1.1 